\section{Effect of Anti-inflammatory Drug Therapy on Clearance of ${ }^{133} \mathrm{Xe}$ from Knee Joints of Patients with Rheumatoid Arthritis}

British Medical fournal, 1969, 3, 278-280

\begin{abstract}
Cummary: The degree of joint inflammation in 13 patients with rheumatoid arthritis, as measured by clinical indices, was reduced by both sodium salicylate and indomethacin. The clearance rate of ${ }^{133} \mathrm{Xe}$ was reduced by indomethacin alone, and showed no correlation with the clinical features.
\end{abstract}

\section{INTRODUCTION}

The assessment of the effects of drug therapy in rheumatoid arthritis remains a difficult problem despite many attempts to construct simple reproducible clinical (Lansbury and Haut, 1956 ; Mandel, 1956 ; Lansbury, 1958, 1966 ; Cooperating Clinics Committee of the American Rheumatism Association, 1965a, 1965b, 1967 ; Mainland, 1967) and laboratory (Bianchi, 1953 ; Hollander et al., 1951 ; Kuipers et al., 1956 ; Davison and Wisham, 1958 ; Nakamura et al., 1967 ; Haberman et al., 1968) indices of joint inflammation.

In an attempt to evolve an objective measure of joint inflammation we have recently studied the clearance of the radioactive gas xenon $\left({ }^{133} \mathrm{Xe}\right)$ from the joint (St. Onge et al., 1968a, 1968b ; Dick et al., 1969a, 1969b). The clearance of this inert isotope, measured as its half-life $\left(\mathrm{T} \frac{1}{2}\right)$, provides a measure of blood flow (Bain and Harper, 1968), and we hoped, therefore, that it would provide an indirect index of inflammation.

In this paper we report the effect of salicylates and of indomethacin on the clearance of ${ }^{133} \mathrm{Xe}$ from the knee joints of patients with rheumatoid arthritis. We have also studied the effect of these drugs on clinical criteria of knee-joint inflammation.

\section{Patients Studied}

Thirteen patients with classical rheumatoid arthritis (Ropes et al., 1958) entered a three-week double-blind trial during which they received three courses of treatment each lasting for one week: enteric-coated sodium salicylate (Entrosalyl) $1.2 \mathrm{~g}$. four times a day, indomethacin (Indocid) $25 \mathrm{mg}$. four times a day, and lactose as placebo. The order of treatment was allocated randomly to the 13 patients, of whom four started on placebo, five on indomethäcin, and four on salicylate (Table I).

Two patients failed to complete the trial and of these one (Case 7) completed one week on sodium salicylate and one week on placebo, but on the third day of the period on indomethacin she developed severe headaches and received no further medication. The second patient (Case 12) completed the first two weeks of the trial successfully-during which he received indomethacin and placebo-but failed to attend for assessment at the end of the third week.

In this double-blind study the physician (P.H.D.), who assessed the patient's response, was unaware of which treatment

TABLE I.-Sequence of Administration of Salicylate, Indomethacin, and TABLE 1.-Sequence of Adacebo in the 13 Patients Studied
Plate

\begin{tabular}{c|l|l|l}
\hline Case No. & Week 1 & Week 2 & Week 3 \\
\hline 1 & Indomethacin & Placebo & Salicylate \\
2 & Placebo & Indomethacin & Salicylate \\
3 & Salicylate & Indomethacin & Placebo \\
4 & Placebo & Indomethacin & Salicylate \\
5 & Indomethacin & Salicylate & Placebo \\
6 & Placebo & Salicylate & Indomethacin \\
7 & Salicylate & Placebo & Placebo \\
8 & Indomethacin & Salicylate & Placebo \\
9 & Indomethacin & Salicylate & Placebo \\
10 & Indomethacin & Palicylate & Indomethacin \\
11 & Salicylate & Indomethacin & Indomethacin \\
12 & Placebo & Placebo & \\
\hline 13 & Salicylate & &
\end{tabular}

was being given. The patients were assessed at the end of each week's treatment. All female patients were post-menopausal and all the patients volunteered to participate in this study with full knowledge of its content.

\title{
Methods of Assessment
}

At each attendance ${ }^{133} \mathrm{Xe}$ studies (St. Onge et al., 1968a, 1968 b ; Dick et al., 1969a, 1969b) were carried out on one knee, which had been selected for study at the beginning of the trial on the basis of the severity of clinical involvement.

With full aseptic precautions about $10 \mu \mathrm{Ci}$ of ${ }^{133} \mathrm{Xe}$ in $1 \mathrm{ml}$. of $0.9 \% \mathrm{NaCl}$ in an air-free syringe was injected into the knee joint through a lateral infrapatellar approach. In all cases an attempt was made to aspirate the joint fully before injecting the isotope; however, in this trial no more than $5 \mathrm{ml}$. could be removed from the joint at any one time. The patient then lay flat and the knee was extended and immobilized with sandbags. The room temperature remained between 65 and $75^{\circ} \mathrm{F}$. $\left(18\right.$ and $24^{\circ}$ C.) and an extraction fan was constantly in operation to prevent the concentration in air of the radioactive gas exhaled by the patient.

A collimated sodium iodide scintillation crystal 1.5 by 1 in. ( 3.8 by $2.5 \mathrm{~cm}$.) connected to an ECHO scalar (type N530G) was positioned 6 in. $(15 \mathrm{~cm}$.) from the medial aspect of the knee joint, the upper border of the patella being used as a reference point. Counts per minute were recorded manually from 5 to 35 minutes following injection, and the background, which was about $5 \%$ of the count rate, was subtracted. The results were then plotted on semilogarithmic graph paper as a function of time, and the halving time of the clearance of ${ }^{133} \mathrm{Xe}$ was obtained from the graph. T $\frac{1}{2}$ values have been shown to be reproducible, with a standard error of the difference in seven paired estimations of 1.9 minutes. In 43 patients with rheumatoid arthritis, 18 with osteoarthritis, and 12 with Reiter's disease the correlation coefficient between clinical knee score and $\mathrm{T} \frac{1}{2}$ value was 0:76 (Dick et al., 1969a). That ${ }^{133} \mathrm{Xe}$ clearance bears an inverse relation to blood flow in many organs has been fully documented (Bain and Harper, 1968), and there is evidence that this relation also holds in the synovial tissues (St. Onge et al., 1968b ; Dick et al., 1969b).

Prior to each ${ }^{133} \mathrm{Xe}$ study the same knee was examined clinically. A history of pain and of stiffness was elicited and graded. The knee was then subjected to firm pressure over the joint margin and the grade of tenderness was recorded. Finally a subjective assessment of the degree of joint swelling was graded. Grading in all cases was on a 0 to 3 basis, where $0=$ "absent," $1=$ "slight," 2 =" moderate," and $3=$ " severe." Thus the maximum total score was 12 for any individual knee.

At the same time at each attendance the patients were questioned regarding side-effects, and the Ritchie index (Ritchie et al., 1968) was used as a measure of total articular status. This index is based on the response of the patient to firm pressure over the joint margin, the response being graded as follows: $0=$ no pain, $+1=$ patient complains of pain, $+2=$ patient complains of pain and winces, $+3=$ patient complains of pain, winces, and withdraws. Certain joints-for example, cervical spine, hips, and mid-tarsal-are examined by passive movement, and some joints are regarded as single units-for example, temporomandibular joints, cervical spine, the sternoclavicular and acromioclavicular joints, the metacarpophalangeal and proximal interphalangeal joints in each hand, and the mid-tarsal and metatarsophalangeal joints in each foot. The maximum possible score for an individual patient is +78. This articular index has been shown to have an acceptable degree of intra-observer reproducibility; the mean intra-observer error difference in 18 patients examined by the same observer within 30 minutes is 1.2 score units, and the standard error of this difference is 1.1 score units (Ritchie et al., 1968). This articular index has also compared favourably with the articular score used by the Cooperating Clinics Com- 
mittee of the American Rheumatism Association (1965b), the correlation coefficient being 0.89 .

\section{RESULTS}

The mean and standard error of the mean (S.E.M.) of the values for the half-life ( $\mathrm{T} \frac{1}{2}$ minutes) of the ${ }^{133} \mathrm{Xe}$ clearance, the knee score, and the articular index while the patients received placebo, sodium salicylate, and indomethacin, respectively, are shown in Table II. The $\mathrm{T}^{\frac{1}{2}}$ values while the patients

TABLE II.-Mean and S.E.M. of Values Obtained on Placebo, Salicylate, and Indomethacin Therepy of the Articular Index, Total Knee Score, and $T \frac{1}{2}$ of the ${ }^{132} \mathrm{Xe}$ Clearance from the Knee

\begin{tabular}{|c|c|c|c|}
\hline & $\begin{array}{c}\mathrm{T}^{\frac{1}{2}} \\
\text { (minutes) }\end{array}$ & $\begin{array}{c}\text { Total } \\
\text { Knee Score }\end{array}$ & $\underset{\text { Index }}{\text { Articular }}$ \\
\hline $\begin{array}{ll}\text { Placebo }(n=13) & . . \\
\text { Salicylates }(n=12) & \\
\text { Indomethacin }(n=12) & \ldots\end{array}$ & $\begin{array}{l}24 \cdot 7 \pm 3 \cdot 1 \\
25 \cdot 3 \pm 1 \cdot 3 \\
32 \cdot 3 \pm 3 \cdot 9\end{array}$ & $\begin{array}{l}7 \cdot 6 \pm 0 \cdot 8 \\
4 \cdot 6 \pm 1 \cdot 1 \\
3 \cdot 8 \pm 0 \cdot 9\end{array}$ & $\begin{array}{r}18 \cdot 6 \pm 2 \cdot 0 \\
8 \cdot 6 \pm 2 \cdot 1 \\
10 \cdot 3 \pm 2 \cdot 9\end{array}$ \\
\hline
\end{tabular}

received indomethacin (mean $32 \cdot 3 \pm$ S.E.M. 3.9) were significantly higher by a paired Student's $t$ 'test $(P<0.05)$ than the values obtained while the patients received placebo (mean $24 \cdot 7 \pm$ S.E.M. 3.1). The T $\frac{1}{2}$ values while the patients received sodium salicylate (mean $25 \cdot 3 \pm 1 \cdot 3$ S.E.M.) were slightly but not significantly higher than the placebo values $(P<0.8)$. There was no significant difference between the $T \frac{1}{2}$ values on sodium salicylate or indomethacin $(P<0 \cdot 2)$. The $T \frac{1}{2}$ values are individually recorded in Table III.

The values obtained for total knee score while the patients received placebo (mean 7.6 \pm S.E.M. 0.8) were significantly higher as tested by a paired Student's $t$ test than the values obtained while the patients received either sodium salicylate $(\mathbf{P}<0.001)$ or indomethacin $(\mathbf{P}<0.001)$, but there was no difference $(P<0.8)$ when the values obtained on sodium salicylate and on indomethacin were compared. Table IV shows the results obtained for each component of the knee score. Both sodium salicylate and indomethacin significantly reduced pain, tenderness, and stiffness; but whereas indomethacin significantly reduced the degree of swelling as compared with placebo $(\mathbf{P}<0.01)$ sodium salicylate did not $(\mathbf{P}<0 \cdot 1)$. There was, however, no significant difference between the degree of reduction of swelling achieved by sodium salicylate compared with

TABLE III.-Individual $T \frac{1}{\frac{1}{2}}$ Values (in Minutes) Recorded While the

\begin{tabular}{c|c|c|c}
\multicolumn{2}{c}{$\begin{array}{c}\text { Patients } \\
\text { Peceived Placebo, Salicylate, and Indomethacin Therapy }\end{array}$} \\
\hline Case No. & Placebo & Salicylate & Indomethacin \\
\hline 1 & 18 & 19 & 19 \\
2 & 20 & 26 & 24 \\
3 & 16 & 31 & 50 \\
4 & 48 & 22 & 55 \\
5 & 23 & 24 & 32 \\
6 & 20 & 27 & 23 \\
7 & 43 & 28 & 52 \\
8 & 14 & 17 & 22 \\
9 & 30 & 38 & 22 \\
10 & 16 & 21 & 42 \\
11 & 13 & 23 & 25 \\
13 & 35 & &
\end{tabular}

indomethacin $(P<0.4)$. No significant correlation was found between the total knee score, or any of its individual components, and the $T \frac{1}{2}$ value.

The values for the articular index (Table II) while the patients received placebo (mean $18 \cdot 6 \pm$ S.E.M. 2.0) were significantly higher by a paired Student's $t$ test than the corresponding values when they were treated with either sodium salicylate (mean $8.6 \pm$ S.E.M. 2.1, $\mathrm{P}<0.001$ ) or indomethacin (mean $10 \cdot 3 \pm$ S.E.M. $2 \cdot 9, \mathrm{P}<0 \cdot 02$ ). There was no significant difference between the values obtained while on sodium salicylate or on indomethacin $(\mathrm{P}<0 \cdot 4)$.

Only one patient (Case 7), who developed severe headaches while receiving indomethacin, failed to complete this trial on account of side-effects. Of the 12 patients on sodium salicylate five complained of mild dyspepsia, which required no treatment, and two developed tinnitus and diminution in hearing during the last two days of salicylate therapy. While on indomethacin four patients complained of headache; and of these two also experienced mild dyspepsia.

\section{Discussion}

"The properly controlled quantitative approach holds the only real hope for dealing with the oncoming flood of new drugs" (Beecher, 1959). This statement made 10 years ago remains true today. In rheumatoid arthritis difficulties lie in the inherent variability of the disease process and in the lack of available methods for measuring the response to drug therapy. Clinical indices, based on the assessment of pain, tenderness, and other subjective features, have been used by many workers (Lansbury and Haut, 1956; Mandel, 1956; Lansbury, 1958, 1966 ; Cooperating Clinics Committee of the American Rheumatism Association, 1965a, 1965b, 1967 ; Mainland, 1967 ; Ritchie et al., 1968), and the difficulties have been discussed by Lansbury (1966) and by Mainland (1967).

In the search for criteria which are less dependent on the reaction of the patient and on the interpretation of the physician than are pain and tenderness, many workers have extended their investigations to the laboratory. Thus Bianchi (1953) studied the clearance of phenol red from the joint, Hollander et al. (1951) investigated intra-articular temperatures, Kuipers et al. (1956) measured the clearance of ${ }^{131}$ I-labelled serum albumin, Davison and Wisham (1958) the clearance of ${ }^{24} \mathrm{Na}$, and Nakamura et al. (1967) the clearance of phenolsulphonphthalein from the joint cavity. More recently Haberman et al. (1968) studied thermography in this context. None of these methods has proved to be entirely satisfactory for all purposes, though the clinical indices, in particular, are of value in clinical practice.

In this paper we have assessed the clearance of ${ }^{133} \mathrm{Xe}$ as a method of measuring the anti-inflammatory effect of drugs. ${ }^{133} \mathrm{Xe}$ is a particularly convenient isotope. Since it has a high blood/air partition coefficient over $90 \%$ of the circulating isotope is cleared from the body by the lungs in one

TABLE IV.-Values Obtained for the Individual Components of the Knee Score while the Patients were Receiving Placbebo, Salicylate, and Indomethacin Therapy

\begin{tabular}{|c|c|c|c|c|c|c|c|c|c|c|c|c|c|c|c|}
\hline \multirow{2}{*}{$\begin{array}{l}\text { Case } \\
\text { No. }\end{array}$} & \multicolumn{5}{|c|}{ Placebo } & \multicolumn{5}{|c|}{ Salicylates } & \multicolumn{5}{|c|}{ Indomethacin } \\
\hline & Pain & Tenderness & Stiffness & Swelling & Total & Pain & Tenderness & Stiffness & Swelling & Total & Pain & Tenderness & Stiffness & Swelling & Total \\
\hline $\begin{array}{r}1 \\
2 \\
3 \\
4 \\
5 \\
6 \\
7 \\
8 \\
9 \\
10 \\
11 \\
12 \\
13\end{array}$ & $\begin{array}{l}3 \\
3 \\
2 \\
1 \\
1 \\
2 \\
3 \\
1 \\
3 \\
1 \\
3 \\
1 \\
3\end{array}$ & $\begin{array}{l}0 \\
2 \\
0 \\
2 \\
2 \\
2 \\
3 \\
0 \\
3 \\
3 \\
3 \\
1 \\
3\end{array}$ & $\begin{array}{l}2 \\
2 \\
0 \\
1 \\
2 \\
0 \\
3 \\
2 \\
2 \\
1 \\
3 \\
1 \\
3\end{array}$ & $\begin{array}{l}3 \\
2 \\
1 \\
1 \\
1 \\
2 \\
3 \\
3 \\
2 \\
2 \\
2 \\
1 \\
3\end{array}$ & $\begin{array}{r}8 \\
9 \\
3 \\
5 \\
6 \\
6 \\
6 \\
12 \\
6 \\
10 \\
7 \\
11 \\
4 \\
12\end{array}$ & $\begin{array}{l}0 \\
2 \\
0 \\
1 \\
0 \\
1 \\
2 \\
0 \\
3 \\
0 \\
2 \\
2 \\
\end{array}$ & $\begin{array}{l}0 \\
2 \\
0 \\
2 \\
0 \\
0 \\
1 \\
0 \\
3 \\
0 \\
0 \\
3\end{array}$ & $\begin{array}{l}0 \\
2 \\
0 \\
0 \\
0 \\
0 \\
2 \\
2 \\
3 \\
0 \\
2 \\
2\end{array}$ & $\begin{array}{l}1 \\
1 \\
1 \\
1 \\
2 \\
0 \\
2 \\
2 \\
3 \\
1 \\
2 \\
2\end{array}$ & $\begin{array}{r}1 \\
7 \\
1 \\
4 \\
2 \\
1 \\
7 \\
4 \\
12 \\
1 \\
6 \\
9\end{array}$ & $\begin{array}{c}0 \\
1 \\
0 \\
1 \\
0 \\
0 \\
0 \\
3 \\
2 \\
2 \\
1 \\
1\end{array}$ & $\begin{array}{l}0 \\
2 \\
0 \\
0 \\
0 \\
0 \\
1 \\
1 \\
3 \\
2 \\
0 \\
1\end{array}$ & $\begin{array}{l}1 \\
1 \\
0 \\
0 \\
0 \\
0 \\
2 \\
3 \\
0 \\
2 \\
0 \\
2\end{array}$ & $\begin{array}{l}1 \\
2 \\
1 \\
0 \\
1 \\
0 \\
2 \\
2 \\
1 \\
2 \\
0 \\
2\end{array}$ & $\begin{array}{l}2 \\
6 \\
1 \\
1 \\
1 \\
0 \\
5 \\
9 \\
6 \\
8 \\
1 \\
6\end{array}$ \\
\hline Mean & $2 \cdot 1$ & 1.8 & 1.7 & $2 \cdot 0$ & $7 \cdot 6$ & $1 \cdot 1$ & 0.9 & $1 \cdot 1$ & 1.5 & $4 \cdot 6$ & 0.9 & 0.8 & 0.9 & 1.1 & 3.8 \\
\hline
\end{tabular}


circulation. Its low emission energy $(80 \mathrm{KeV})$ results in the exposure of both patient and investigator to a low radiation hazard.

${ }^{133} \mathrm{Xe}$ has been used to measure the blood flow through many organs and tissues-for example, muscle, brain, adipose tissue, etc. (Bain and Harper, 1968). The method of indicator techniques for measuring blood flow, based on the Fick principle, was modified by Kety (1949) and subsequently applied to ${ }^{133} \mathrm{Xe}$ by Lassen (1963) and Lassen et al. (1964), who measured blood flow by this technique. If the tracer substance is freely diffusible, and provided that the halving-time ( $\left(\frac{1}{2}\right)$ of the clearance of the substance is known, then blood flow through the tissue is inversely proportional to the observed $\mathrm{T} \frac{1}{2}$ value. Since semilog plots of the results could be described by a monoexponential function, $T \frac{1}{2}$ values could be readily obtained. Provided that the diffusion coefficient of ${ }^{133} \mathrm{Xe}$ in synovial tissue is similar to that in saline $\left(1.75 \times 10^{-5} \mathrm{sq}\right.$. $\mathrm{cm}$. $/ \mathrm{sec}$. at $37^{\circ} \mathrm{C}$.), then it can be shown that $50 \%$ of the injected isotope will diffuse into the membrane in 10 to 20 seconds. Since the $T \frac{1}{2}$ values were in the region of $20+$ minutes, the clearance of the isotope will not be limited by diffusion. Thus the $\mathrm{T} \frac{1}{2}$ values can be assumed to bear an inverse relation to blood flow (St. Onge et al., 1968b ; Dick et al., 1969b). Previously (Dick et al., 1969a) $\mathrm{T}_{2}^{\frac{1}{2}}$ values have been shown to be reproducible and to bear an inverse relation to clinical indices of knee-joint inflammation.

The "test" of any new method of assessment is to evaluate it in a relevant clinical situation. Thus in the context of an index of inflammation it is essential to show that it works under the conditions of a clinical trial. In this study we have tested the ${ }^{133} \mathrm{Xe}$ clearance technique in such a situation. Sodium salicylate, indomethacin, and placebo were each given for one week in a double-blind trial. Though the $\mathrm{T} \frac{1}{2}$ values showed a significant change with indomethacin, there was no significant change with aspirin. The dose of sodium salicylate was adequate ( $5 \mathrm{~g}$. per day), and indeed two patients developed salicylism. Furthermore, both local (knee score) and general (articular index) clinical indices showed that aspirin exerted significant clinical benefit. Since the ${ }^{133} \mathrm{Xe}$ clearance did not show changes with the "sheet anchor" of drug treatment it is doubtful if this technique will be of value-on its own-in the clinical assessment of the response of rheumatoid arthritis to anti-inflammatory therapy.

The results are of some interest, however, since indomethacin significantly altered the $T \frac{1}{2}$ values whereas aspirin did not. There are several possible explanations of this phenomenon. Aspirin may exert a weaker anti-inflammatory effect than does indomethacin in these doses. In animals indomethacin exerted a more powerful inhibitory effect on carrageenin oedema than aspirin (Winter, 1964), and this was confirmed by Boris and Stevenson (1965). Clinical experience (Sunshine et al., 1964 ; Pinals and Frank, 1967), however, suggests that these drugs in adequate anti-inflammatory doses are approximately equipotent, though Pitkeathly et al. (1966) found a greater improvement in grip strength with indomethacin than with aspirin. It is noteworthy that in this study indomethacin, but not aspirin, reduced swelling significantly. Nevertheless, all other clinical indices showed significant change with both drugs.

A further possibility is that indomethacin exerts a more selective effect on the vascular component of inflammation than does aspirin. This would explain the alteration in a criterion by which blood flow is measured. There is evidence that indomethacin exerts an effect on cerebral blood vessels (Vecchio and Fontana, 1965). Sicuteri (1965) noted that indomethacin decreased cerebrospinal fluid pressure and raised the retinal artery pressure, and concluded that indomethacin has a vasoreactive effect on cerebral blood vessels. The ${ }^{133} \mathrm{Xe}$ technique may be recording similar changes on the peripheral vascular system in the knee.

This study has shown that the rate of clearance of ${ }^{133} \mathrm{Xe}$ from the knee joint and the clinical indices of inflammation may be altered by indomethacin therapy. The beneficial effect of salicylates, however, as measured by the clinical indices, is not accompanied by an alteration in the ${ }^{133} \mathrm{Xe}$ clearance technique. Further work on this question is clearly required, and this is in progress.

This work would not have been possible without financial support from the Arthritis and Rheumatism Council for Research in Great Britain, to whom we are indebted.

C. DICK, M.B., CH.B., M.R.C.P., Registrar in Medicine.

P. H. DICK, Medical Student.

G. NUKI, M.B., M.R.C.P., Ciba Clinical Research Fellow.

K. WhaleY, M.B., M.R.C.P., Registrar in Medicine.

J. A. BOYLE,* M.D., M.R.C.P., M.R.C.P.ED., Harkness Travelling Fellow.

A. SHENKIN, B.SC., Medical Student.

W. W. DOWNIE, M.B., CH.B., B.SC., Arthritis and Rheumatism Council Lecturer in Medicine.

W. W. BuchanaN, M.D., F.R.C.P.GLASG., M.R.C.P.ED., Consultant Physician in Medicine.

Centre for Rheumatic Diseases and the University Department of Medicine, Glasgow C. 4 .

* Present address: Department of Biochemical Genetics, NIAMD, NIH, Bethesda, Maryland, U.S.A.

\section{REFERENCES}

Bain, W. H. and Harper, A. M. (1968). Blood Flow Through Organs and Tissues. Edinburgh and London, Livingstone.

Beecher, H. K. (1959). Measurement of Subjective Responses: Quantitative Effects of Drugs. New York, Oxford University Press.

Bianchi, C. (1953). British fournal of Pharmacology, 8, 130.

Cooperating Clinics Committee of the American Rheumatism Association (1965a), Bulletin on Rheumatic Diseases, 16, 388.

Cooperating Clinics Committee of the American Rheumatism Association (1965b). Arthritis and Rheumatism, 8, 302.

Cooperating Clinics committee of the American Rheumatism Association (1967). Clinical Pharmacology and Therapeutics, 8, 11.

Davison, S., and Wisham, L. H. (1958). Fournal of Clinical Investigation, 37, 389

Dick, C., et al. (1969a). Xenon Studies in Normal and Diseased Joints. In preparation.

Dick, C., et al. (1969b). Measurement of synovial blood flow in man using xenon $\left({ }^{133} \mathrm{Xe}\right)$. In preparation.

Haberman, J. D., Ehrlich, G. E., and Levenson, C. (1968). Archives of Physical Medicine and Rehabilitation, 49, 187.

Hollander, J. L., Stoner, E. K. Brown, E. M., jun., and deMoor, P. (1951). Fournal of Clinical Investigation, 30, 701 .

Kety, S. S. (1949). American Heart fournal, 38, 321.

Kuipers, R. K. W., Franke, C., and Robert, W. N. (1956). Acto Rheumatologica Scandinavica, $2,81$.

Lansbury, J. (1958). Arthritis and Rheumatism, 1, 505.

Lansbury, J. (1966). In Arthritis and Allied Conditions, 7th ed., edited by J. L. Hollander. Philadelphia, Lea and Febiger.

Lansbury, J., and Haut, D. D. (1956). American Yournal of Medical Science, 232, 150 .

Lassen, N. A. (1963). VIII Conference of the Italian Society of Biology and Medicine, Pisa.

Lassen, N. A., Lindbjerg, J., and Munck, O. (1964). Lancet, 1, 686.

Mainland, D. (1967). Arthritis and Rheumatism, 10, 71.

Mandel, L. (1956). Canadian Medical Association fournal, 74, 515.

Nakamura, R., Asai, H., Sonozaki, H., and Nagano, M. (1967). Annals of the Rheumatic Diseases, 26, 246.

Pinals, R. S., and Frank, S. (1967). New England fournal of Medicine, 276, 512 .

Pitkeathly, D. A., Banerjee, N. R., Harris, R., and Sharp, J. (1966). Annals of the Rheumatic Diseases, 25, 334.

Ritchie, D. M., et al. (1968). Quarterly fournal of Medicine, 37, 393.

Ropes, M. W., Bennet, G. A., Cobb, S., Jacox, R., and Jessar, R. A. (1958) Bulletin on Rheumatic Diseases, 9 , 175 .

St. Onge, R. Bulletin on Rheumatic Diseases, 9, 175. Dick, W. C., Bell, G., and Boyle, J. A. (1968a). Annals Onge, R. A., Dick, W. C., Bell, G., and
of the Rheumatic Diseases, 27,163 .

St. Onge, R. A., et al. (1968b). Arthritis and Rheumatism, 11, 508.

Sicuteri, F. (1965). In Proceedings of Symposium on Non-Steroidal Antiinflammatory Drugs, p. 159. Turin, Minerva Medica.

Sunshine, A., Laska, E., Meisner, M., and Morgan, S. (1964). Clinical Pharmacology and Therapeutics, 5,700 .

Winter, C. A. (1964). Excerpta Medica International Congress Series, No. 82 , p. 190.

Vecchio, C., and Fontana, S. (1965). In Proceedings of Symposium on Non-steroidal Anti-inflammatory Drugs, p. 166. Turin, Minerva Medica. 